\title{
The association of serum selenium with serum lipids in US adults
}

\author{
Nuan Wen ${ }^{1}$ \\ ${ }^{1}$ High School Affiliated to Shanghai Jiao Tong University, Shanghai 200439, China
}

\begin{abstract}
High selenium concentrations were associated with cardiovascular diseases, type 2 diabetes, and central nervous disorders. The author examined the relation of serum selenium concentration with serum lipids levels with the use of the National Health and Nutrition Examination Survey (NHANES) 2017-2018. 759 adults aged more than 20 years old from NHANES 2017-2018 were examined in the analysis. Serum selenium was measured by mass spectrometry. Triglyceride, HDL cholesterol, and total cholesterol were measured through enzymatical methods. LDL cholesterol was calculated then. Comparing Q4 to Q1 of serum selenium, the multivariable adjusted average differences $(95 \% \mathrm{CI})$ in triglyceride, HDL cholesterol, LDL cholesterol, and total cholesterol were $21.3 \mathrm{mg} / \mathrm{dL}$ (9.1, $33.4 \mathrm{mg} / \mathrm{dL}), 2.3 \mathrm{mg} / \mathrm{dL}(-0.6,5.2 \mathrm{mg} / \mathrm{dL}), 6.3$ $\mathrm{mg} / \mathrm{dL}(-1.3,13.9 \mathrm{mg} / \mathrm{dL}), 12.8$ (95\% CI: 4.2, $21.5 \mathrm{mg} / \mathrm{dL})$, respectively. Hence, The increasing serum selenium concentration is associated with increasing triglyceride, total cholesterol, HDL cholesterol, and LDL cholesterol among US adults.
\end{abstract}

\section{Introduction}

Selenium is incorporated into selenoproteins that have antioxidant effects1. Recently, the discovery of the association between many diseases and selenoproteins has drawn considerable attention. Increasing selenium levels were related higher prevalence of type 2 diabetes, cardiovascular diseases, and central nervous disorders2345. A study conducted in 2010 found that in the US, the whole population has selenium intake over $55 \mu \mathrm{g} / \mathrm{d}$, the selenium intake of the Recommended Dietary Allowance6. Another study stated that in the United States, almost all US adults have serum selenium concentration over $95 \mathrm{ng} / \mathrm{mL}$, well beyond the maximum threshold to activate glutathione peroxidases7. Since selenium has gained much interest in treating certain diseases, it is necessary to first evaluate the effect of serum selenium on the nutrition profile. Data from NHANE 2017-2018 is used for statistical analysis. The author aims to find out the relationship between the serum selenium concentration and the lipid levels.

\section{Methods}

NHANES 2017-2018 selected samples to represent the US population, about 5000 people each year[16]. The author used data from NHANES 2017-2018, the latest data in access. 5596 participants are selected from NHANES 2017-2018 with age $>=20$. Participants with missing education information, BMI, fasting glucose, serum selenium, diastolic blood pressure, systolic blood pressure, hypertension, diabetes, HDL cholesterol, LDL cholesterol, total cholesterol, triglyceride, alcohol consumption, smoking, total fat intake, total cholesterol intake, and dietary supplements, were excluded. 759 samples were left finally.

\subsection{Serum selenium}

Serum selenium was measured by Inorganic and Radiation Analytical Toxicology Branch, Division of Laboratory Sciences, National Center for Environmental Health using blood multi-element analysis by inductively coupled plasma-dynamic reaction cell-mass spectrometry (ICP-DRC-MS)8.

\subsection{Serum lipids}

Total cholesterol concentrations and HDL cholesterol concentrations were measured by Advanced Research and Diagnostic Laboratory (ARDL), University of Minnesota, using Roche Cobas 60008. Triglyceride concentrations were measured by Advanced Research and Diagnostic Laboratory, University of Minnesota, using Cobas 6000 Chemistry Analyzer8. LDL cholesterol concentrations were calculated with the use of the Friedewald formula8.

\subsection{Other variables}

Sex, age, ethnicity, smoking, and alcohol consumption, education, use of dietary supplements, total fat intake, and total cholesterol intake were self-reported. Body

\footnotetext{
* Corresponding author: wennuan@jdfzib.org
} 
mass index was calculated by $\frac{\text { weightinkilogram }}{\text { (heightinmeters })^{2}}$.

Fasting glucose concentrations were measured by Diabetes Diagnostic Laboratory, University of Missouri, 1 Hospital Dr. Columbia, using Roche/Hitachi Cobas C Chemistry Analyzer - C31189.

\subsection{Statistical methods}

Adjusted for the weighted population, samples were divided into four quartiles based on the serum selenium concentration. The multivariable linear regression was used to measure the differences in concentrations of total cholesterol, HDL cholesterol, LDL cholesterol, triglyceride, using the lowest quartile as reference level. Three models with different adjustments were made. Model 1 was adjusted for sex, age, and ethnicity. Model 2 was further adjusted for hypertension, body mass index, education, alcohol consumption, and smoking. Model 3 was further adjusted for fasting glucose, systolic blood pressure, diastolic blood pressure, diabetes, dietary supplements, total fat intake, and total cholesterol intake (Table 2). Statistical analyses and graph plotting were performed in the RStudio (version 4.0.2).

\section{Results}

The mean (standard deviation) serum selenium concentration of the participants was $189.6(26.7) \mu \mathrm{g} / \mathrm{L}$. Mean total cholesterol, HDL cholesterol, LDL cholesterol, and triglyceride concentrations were 184.7 (43.1), 52.0 (16.1), 110.2 (37.6), and 113.1 (63.3) mg/dL, respectively. Men, non-Hispanic White, currently drinking, and non-smoking were is very likely to have a high serum selenium concentration (Table 1). Serum selenium concentrations were positively associated with dietary supplements, and with drinking, and inversely associated with current smoking (Table 1).

Regarding the total cholesterol, HDL cholesterol, LDL cholesterol, and triglyceride, the multivariable adjusted average differences $(95 \% \mathrm{CI})$ between Q4 and Q1 were $12.8(4.2,21.5 \mathrm{mg} / \mathrm{dL}), 2.3 \mathrm{mg} / \mathrm{dL}(-0.6,5.2$ $\mathrm{mg} / \mathrm{dL}), 6.3 \mathrm{mg} / \mathrm{dL}(-1.3,13.9 \mathrm{mg} / \mathrm{dL}), 21.3 \mathrm{mg} / \mathrm{dL}(9.1$, $33.4 \mathrm{mg} / \mathrm{dL}$ ) (Table 2 Model 3). Linear trend tests were applied and the results were statistically significant for LDL cholesterol, total cholesterol, and triglyceride, except for HDL cholesterol.

In spline regression models (Figure 1), total cholesterol and LDL cholesterol concentration increased up to $20 \mathrm{mg} / \mathrm{dL}$ as selenium concentration increases from $100 \mu \mathrm{g} / \mathrm{L}$. HDL cholesterol levels first increased at a slow rate but increased rapidly after the selenium concentration reached $200 \mu \mathrm{g} / \mathrm{L}$. The triglyceride was $\mathrm{N}$-shaped.

Table 1 Baseline characteristics of the participants divided into four quartiles

\begin{tabular}{|c|c|c|c|c|c|c|}
\hline & Overall & $\begin{array}{c}\text { Q1 } \\
(<173.3 \mu \mathrm{g} / \mathrm{L})\end{array}$ & $\begin{array}{c}\text { Q2 } \\
\begin{array}{c}(173.3-187.8 \\
\mu \mathrm{g} / \mathrm{L})\end{array}\end{array}$ & $\begin{array}{c}\text { Q3 } \\
\begin{array}{c}(187.8-204.3 \\
\mu \mathrm{g} / \mathrm{L})\end{array}\end{array}$ & $\begin{array}{c}\text { Q4 } \\
(>204.3 \mu \mathrm{g} / \mathrm{L})\end{array}$ & $\mathrm{p}$ trend \\
\hline $\mathrm{n}$ & 759 & 190 & 189 & 190 & 190 & \\
\hline Sex, male $(\%)$ & $448(59.0)$ & $102(53.7)$ & $109(57.7)$ & $114(60.0)$ & $123(64.7)$ & 0.05 \\
\hline Age $(y)$ & $53.51(16.65)$ & $53.81(17.28)$ & $53.51(17.39)$ & $52.99(16.34)$ & $53.74(15.67)$ & 0.963 \\
\hline Race (\%) & & & & & & 0.036 \\
\hline Mexican American & $101(13.3)$ & $22(11.6)$ & $26(13.8)$ & $24(12.6)$ & $29(15.3)$ & \\
\hline Other Hispanic & $60(7.9)$ & $13(6.8)$ & $16(8.5)$ & $14(7.4)$ & $17(8.9)$ & \\
\hline Non-Hispanic White & $324(42.7)$ & $81(42.6)$ & $68(36.0)$ & $88(46.3)$ & $87(45.8)$ & \\
\hline Non-Hispanic Black & $170(22.4)$ & $56(29.5)$ & $49(25.9)$ & $40(21.1)$ & $25(13.2)$ & \\
\hline Other & $104(13.7)$ & $18(9.5)$ & $30(15.9)$ & $24(12.6)$ & $32(16.8)$ & \\
\hline $\begin{array}{l}\text { Body mass index } \\
(\mathrm{kg} / \mathrm{m} 2)\end{array}$ & $30.34(7.84)$ & $29.86(8.02)$ & $30.22(7.35)$ & $30.09(6.95)$ & $31.18(8.91)$ & 0.371 \\
\hline Hypertension (\%) & $330(43.5)$ & $81(42.6)$ & $83(43.9)$ & $81(42.6)$ & $85(44.7)$ & 0.771 \\
\hline Diabetes (\%) & $155(20.4)$ & $34(17.9)$ & $42(22.2)$ & $32(16.8)$ & $47(24.7)$ & N/A \\
\hline $\begin{array}{l}\text { Current alcohol } \\
\text { consumption (\%) }\end{array}$ & $375(49.4)$ & $83(43.7)$ & $90(47.6)$ & $96(50.5)$ & $106(55.8)$ & 0.02 \\
\hline Current smoking (\%) & $322(42.4)$ & $93(48.9)$ & $87(46.0)$ & $75(39.5)$ & $67(35.3)$ & 0.03 \\
\hline Total fat intake $(\mathrm{g} / \mathrm{d})$ & $86.22(51.11)$ & $89.99(57.18)$ & $84.42(43.52)$ & $88.20(55.29)$ & $82.25(47.21)$ & 0.441 \\
\hline $\begin{array}{l}\text { Total cholesterol } \\
\text { intake }(\mathrm{mg} / \mathrm{d})\end{array}$ & $309.08(261.29)$ & $329.68(246.37)$ & $319.56(273.78)$ & $296.67(246.95)$ & $290.46(276.66)$ & 0.411 \\
\hline $\begin{array}{l}\text { Dietary supplements } \\
(\%)\end{array}$ & $302(39.8)$ & $59(31.1)$ & $70(37.0)$ & $89(46.8)$ & $84(44.2)$ & 0.007 \\
\hline
\end{tabular}

Values are weighted means (standard deviation) for continuous or percentage for categorical variables. 
Table 2 Comparing the differences $(95 \% \mathrm{CI})$ in quartiles of serum selenium concentration

\begin{tabular}{|c|c|c|c|c|c|}
\hline & $\begin{array}{c}\text { Q1 } \\
(<173.3 \mu \mathrm{g} / \mathrm{L})\end{array}$ & $\begin{array}{c}\text { Q2 } \\
(173.3-187.8 \\
\mu \mathrm{g} / \mathrm{L})\end{array}$ & $\begin{array}{c}\text { Q3 } \\
(187.8-204.3 \\
\mu \mathrm{g} / \mathrm{L})\end{array}$ & $\begin{array}{c}\text { Q4 } \\
(>204.3 \mu \mathrm{g} / \mathrm{L})\end{array}$ & $\mathrm{p}$ trend \\
\hline HDL cholesterol (mg/dL) & 51.9 & 51.1 & 52.6 & 52.8 & \\
\hline Model 1 & 0.00 (reference) & $-0.3(-3.4,2.8)$ & $1.8(-1.3,4.9)$ & $2.0(-1,5.2)$ & 0.02 \\
\hline Model 2 & 0.00 (reference) & $-0.2(-3.1,2.6)$ & $1.4(-1.5,4.2)$ & $2.1(-0.8,5.0)$ & 0.3 \\
\hline Model 3 & 0.00 (reference) & $-0.2(-3.1,2.6)$ & $1.1(-1.8,3.9)$ & $2.3(-0.6,5.2)$ & $<0.001$ \\
\hline LDL cholesterol (mg/dL) & 108.0 & 108.8 & 110.3 & 113.6 & \\
\hline Model 1 & 0.00 (reference) & $0.6(-7.1,8.2)$ & $2.2(-5.4,9.8)$ & $5.3(-2.3,13.0)$ & $<0.001$ \\
\hline Model 2 & 0.00 (reference) & $0.8(-6.8,8.4)$ & $2.7(-5.0,10.3)$ & $5.9(-1.9,13.6)$ & 0.001 \\
\hline Model 3 & 0.00 (reference) & $1.5(-5.9,8.9)$ & $2.8(-4.7,10.3)$ & $6.3(-1.3,13.9)$ & $<0.001$ \\
\hline Total cholesterol (mg/dL) & 180.6 & 180.7 & 185.2 & 192.5 & \\
\hline Model 1 & 0.00 (reference) & $0.0(-8.7,8.6)$ & $5.1(-3.5,13.7)$ & $12.4(3.7,21.2)$ & $<0.001$ \\
\hline Model 2 & 0.00 (reference) & $0.1(-8.5,8.6)$ & $5.1(-3.5,13.7)$ & $12.6(3.9,21.3)$ & $<0.001$ \\
\hline Model 3 & 0.00 (reference) & $0.8(-7.6,9.2)$ & $4.9(-3.6,13.3)$ & $12.8(4.2,21.5)$ & $<0.001$ \\
\hline Triglyceride (mg/dL) & 103.3 & 103.5 & 111.3 & 134.3 & \\
\hline Model 1 & 0.00 (reference) & $-1.5(-13.7,10.8)$ & $5.5(-6.8,17.8)$ & $25.3(13.0,37.8)$ & $<0.001$ \\
\hline Model 2 & 0.00 (reference) & $-2.3(-14.3,9.6)$ & $5.6(-6.4,17.5)$ & $23.1(11.0,35.3)$ & $<0.001$ \\
\hline Model 3 & 0.00 (reference) & $-2.5(-14.4,9.3)$ & $5.1(-6.8,17.1)$ & $21.3(9.1,33.4)$ & $<0.001$ \\
\hline
\end{tabular}

\section{Discussion}

In the present cross-sectional study, the results suggest that the selenium concentration increases as the total, HDL, LDL cholesterol, and triglyceride levels increase. The detailed method description and quality assurance of NHANES 2017-2018 strengthen the solidity of the findings. Strong linear associations of serum selenium with HDL cholesterol, total cholesterol, and LDL cholesterol were observed except that both curves flatten when the selenium concentration reached $200 \mu \mathrm{g} / \mathrm{L}$ (Figure 1.). The effect of high selenium concentration should be evaluated when dealing with diseases discussed earlier.

Serum concentration was also found positively associated with lipid levels in earlier cross-sectional studies with the use of NHANES III and NHANES 2003-200467. In those studies, the mean serum selenium concentrations were $125.7 \mu \mathrm{g} / \mathrm{L}$ and $136.7 \mu \mathrm{g} / \mathrm{L}$, respectively. An increase in serum selenium concentration over time was observed which could result from the overnutrition at present. Alternatively, selenium is used as a drug. The increasing trend is worth noticing. Collaborating with the current findings, additional concerns should be raised considering the potential cause of cardiovascular diseases and metabolic disorders.
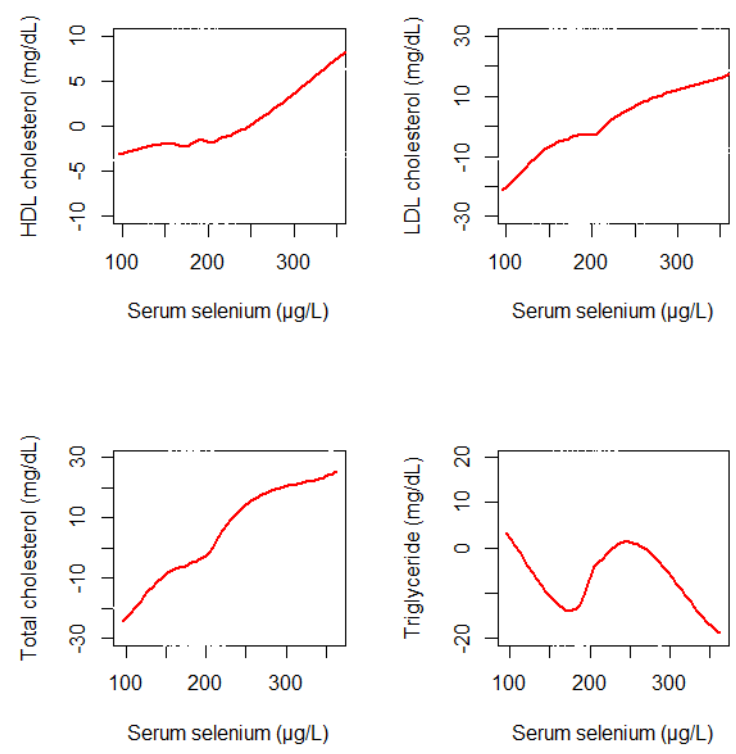

Fig.1. Result based on Model 3

Several other studies have also focused on this topic. An earlier meta-analysis of serum selenium and lipid levels discovered a strong association between the increase of serum selenium concentration and the increase of total cholesterol, but the serum selenium did not affect other serum lipids[10]. In a study conducted in Spain, statistically significant associations between lipid levels and plasma selenium were observed[12]. In another meta-analysis study, selenium supplementation reduced the lipid levels.11. A randomized controlled trial found that lipid levels of patients with metabolic 
disorders, despite assigned selenium supplementation, were not affected. Moreover, in 1235 young Finns, serum selenium levels were positively associated with total cholesterol, HDL cholesterol, and LDL cholesterol[14]. Finally, lipid levels increased rapidly when serum selenium concentration increased in the Taiwanese elderly[15]. The inconsistencies could be explained by the difference in the population that these studies chose. Different populations have different mean serum selenium concentrations, so the effect of serum selenium is not consistent. Besides, the incidence rate of drinking and smoking varies across regions, so the influence of these two variables on the effect of serum selenium concentration varies. This may imply that the relationship between serum selenium concentration and lipid profile is readily subjected to other baseline characteristics, so a population-specific model may be needed. It can result in a inconsistent medical policies across the countries. Difficulties in the global synchronization of information on selenium prescription hinders the study of local serum selenium pattern which could have made use of the significant outcomes from other countries.

The drawback of the cross-sectional study is the inability to establish the cause and effect relationship between the variables. Therefore, studies with controlled variables and mechanistic studies among the population with different characteristics are needed to establish the cause and effect relation.

\section{Conclusion}

US adults with increasing selenium concentration were likely to have increased concentrations of total cholesterol, HDL cholesterol, LDL cholesterol, and triglycerides. To make the results more valid, larger sample size is needed for generalization. Of many years NHANES has conducted selenium laboratory examination, a few of them has undergone cross-sectional analysis, thus a space for further investigation. Also, future studies are needed to prove the causality of high serum selenium and high serum lipid levels. The mechanisms of selenium-induced increase in lipid levels could provide other perspectives on the treatment of metabolic disorders. Moreover, an increase in serum selenium in the US population was observed previously. A further study could assess the long-term effects of the high serum selenium on the human body. Researches on the diet that influences selenium intake could contribute to explain the rising incidence of certain diseases these days.

\section{Acknowledgment}

I would like to express my appreciation to Professor Wang for his professional guidance and valuable support on this project. I must also thank Mr. Yi for his technical assistance in handling the $\mathrm{R}$ language.

\section{Reference}

1. Rayman, M. P. (2012). Selenium and human health. The Lancet, 379(9822), 1256-1268. https://doi.org/10.1016/S0140-6736(11)61452-9

2. Benstoem, C., Goetzenich, A., Kraemer, S., Borosch, S., Manzanares, W., Hardy, G., \& Stoppe, C. (2015). Selenium and its supplementation in cardiovascular disease-what do we know? Nutrients, 7(5), 3094-3118. https://doi.org/10.3390/nu7053094

3. Bleys, J., Navas-Acien, A., \& Guallar, E. (2007). Serum selenium and diabetes in U.S. adults. Diabetes Care, 30(4), 829-834. https://doi.org/10.2337/dc06-1726

4. Steinbrenner, H., \& Sies, H. (2013). Selenium homeostasis and antioxidant selenoproteins in brain: Implications for disorders in the central nervous system. Archives of Biochemistry and Biophysics, 536(2), 152-157. https://doi.org/10.1016/j.abb.2013.02.021

5. Stranges, S., Marshall, J. R., Natarajan, R., Donahue, R. P., Trevisan, M., Combs, G. F., Cappuccio, F. P., Ceriello, A., \& Reid, M. E. (2007). Effects of long-term selenium supplementation on the incidence of type 2 diabetes: A randomized trial. Annals of Internal Medicine, 147(4), 217-223. https://doi.org/10.7326/0003-4819-147-4-200708210 $-00175$

6. Laclaustra, M., Stranges, S., Navas-Acien, A., Ordovas, J. M., \& Guallar, E. (2010). Serum selenium and serum lipids in US adults: National Health and Nutrition Examination Survey (NHANES) 2003-2004. Atherosclerosis, 210(2), 643-648.

https://doi.org/10.1016/j.atherosclerosis.2010.01.005

7. Bleys, J., Navas-Acien, A., Stranges, S., Menke, A., Miller, E. R., \& Guallar, E. (2008). Serum selenium and serum lipids in US adults. American Journal of Clinical Nutrition, 88(2), 416-423. https://doi.org/10.1093/ajen/88.2.416

8. NHANES 2017-2018 Laboratory Methods. National Health and Nutrition Examination Survey, Centers for Disease Control and Prevention. Retrieved February 15, 2021, from https://wwwn.cdc.gov/nchs/nhanes/continuousnhane s/labmethods.aspx?BeginYear $=2017$

9. NHANES 2017-2018 Procedure Manuals. National Health and Nutrition Examination Survey, Centers for Disease Control and Prevention. Retrieved February 15, 2021, from https://wwwn.cdc.gov/nchs/nhanes/continuousnhane s/manuals.aspx?BeginYear=2017

10. Yousefi Rad, E., Falahi, E., Saboori, S., Asbaghi, O., Birjandi, M., Hesami, S., \& Aghayan, M. (2019). Effect of selenium supplementation on lipid profile levels: An updated systematic review and meta-analysis of randomized controlled clinical trials. Obesity Medicine, 15.

https://doi.org/10.1016/j.obmed.2019.100113 
11. Hasani, M., Djalalinia, S., Sharifi, F., Varmaghani, M., Zarei, M., Abdar, M. E., Asayesh, H., Noroozi, M., Kasaeian, A., Gorabi, A. M., \& Qorbani, M. (2018). Effect of Selenium Supplementation on Lipid Profile: A Systematic Review and Meta-Analysis. Hormone and metabolic research $=$ Hormon- und Stoffwechselforschung $=$ Hormones et metabolisme, 50(10), 715-727. https://doi.org/10.1055/a-0749-6655

12. Galan-Chilet, I., Guallar, E., Martin-Escudero, J. C., De Marco, G., Dominguez-Lucas, A., Gonzalez-Manzano, I., Lopez-Izquierdo, R., Redon, J., Chaves, F. J., \& Tellez-Plaza, M. (2015). Do genes modify the association of selenium and lipid levels? Antioxidants and Redox Signaling, 22(15), 1352-1362. https://doi.org/10.1089/ars.2015.6248

13. Reza Tabrizi1, Maryam Akbari, Mahmood Moosazadeh, Kamran B. Lankarani, Seyed Taghi Heydari, Fariba Kolahdooz, Ali Akbar Mohammadi, Azade Shabani, Bita Badehnoosh, Mehri Jamilian, Amin Assarian, Zatollah Asemi. (2017). The Effects of Selenium Supplementation on Glucose Metabolism and Lipid Profiles Among Patients with Metabolic Diseases: A Systematic Review and Meta-Analysis of Randomized Controlled Trials. Horm Metab Res. https://doi.org/10.1055/s-0043-119544. 